\title{
Seventeen Primes in Arithmetic Progression
}

\section{By Sol Weintraub}

Abstract. Two sets of primes in arithmetic progression are listed. One is a set of 17 primes and the second is a set of six consecutive primes.

A computer search revealed the following sequence of 17 primes in arithmetic progression:

$\begin{array}{rrr}\text { First term: } & 3430751869 \\ \text { Last term: } & 4827507229 \\ \text { Difference: } & 87297210\end{array}$

The common difference equals $2 \cdot 3^{3} \cdot 5 \cdot 7 \cdot 11 \cdot 13 \cdot 17 \cdot 19$.

The previous record of 16 primes in arithmetic progression was found by S. C. Root in 1969 [1]. I have found 7 other sequences of 16 primes (the smallest starting at 13816843 with a common difference of 236366130 ), but the foregoing is the only case of more than 16 primes known to me.

On a related problem I found a second set of six consecutive primes in arithmetic progression near $10^{15}$ :

$$
999900067719989+30 t, \quad t=0(1) 5 .
$$

The smallest such sextet was found by Lander and Parkin [2] at $121174811+30 t$, $t=0(1) 5$.

Queens College

City University of New York

Flushing, New York 11367

1. E. KARST, "12 to 16 primes in arithmetical progressions," J. Recreational Math., v. 2, 1969, pp. 214-215.

2. L. J. LANDER \& T. R. PARKIN, "Consecutive primes in arithmetic progression," Math. Comp., v. 21, 1967 , p. 489.

Received February 28, 1977; revised March 31, 1977.

AMS (MOS) subject classifications (1970). Primary $10 \mathrm{~A} 25$.

Key words and phrases. Prime, primes in arithmetic progression. 